\title{
Solitary Confinement by Another Name Remains Solitary Charles Diorio
}

$\mathrm{T}$ he United States Department of Justice in the District of Massachusetts is currently investigating whether the Massachusetts Department of Correction engages in a pattern or practice of violating the constitutional rights of prisoners through 1) the use of prolonged restrictive housing and/or 2) medical care for geriatric and palliative care prisoners. ${ }^{1}$ Today, Massachusetts prisons are scrambling to rebrand their solitary confinement units so as to avoid such scrutiny and possible federal sanctions or injunctive receivership.

Department of Correction administrators are carefully renaming and reinventing various levels of solitary confinement within their correctional facilities. Special Management Units (SMU), for instance, are becoming Restrictive Housing Units (RHU). Recently, an entirely new unit is being developed known as the Secure Adjustment Unit (SAU) and prisoners branded as 'inmates' - who commit serious violations, like using a weapon during a fight, continue to be placed in the Disciplinary Detention Unit (DDU). There is no shortage of branding in the Massachusetts Department of Correction for what is effectively solitary confinement or administrative segregation.

Recently, I spent the middle part of June in a solitary confinement cell in MCI-Concord. For fifteen days, I witnessed an evolution whereby the SMU transitioned into the RHU. What I witnessed offers hope for reforms being made, which may translate into the development of some humanity previously lacking within this institution.

SMU, DDU, SAU and RHU all represent an obfuscatory alphabet soup the Massachusetts Department of Correction uses for what is effectively seclusion and restraint. Ever since the public, courts and legislatures began to scrutinize these blighted, poorly administered isolation units more closely, changes have started to come. In some cases, the change has been dramatic. ${ }^{2}$

Historically, 'segregation' and 'isolation' units have officially been places of indefinite detention for non-conformists whose behaviour is said to require their segregation from the general institutional population. ${ }^{3}$ According to the law, "[s] uch a unit should provide regular meals, fully furnished cells, limited recreational facilities, library, visits, and radio, etc...". ${ }^{4}$ In the past, segregation was envisioned to remove so-called recalcitrant prisoners from general population, not as punishment. 
On 13 June 2020 I got into a bloody fight with a fellow prisoner in the woodshop industry program. I was hit in the head by a 2 x 4 and electric drill. Defeated and bleeding, I was taken by ambulance to a local hospital for a CT-SCAN. Returning to MCI-Concord, I was admitted overnight for observation in the Health Services Unit (HSU). It is important to note I was never given a blanket, eyeglasses, or sheets during my time in the HSU. ${ }^{5}$

The following day, I was handcuffed and removed from the HSU, and then sent to the RHU, formerly called the SMU. My new cell was swept and there was a stink from a toilet that looked as if it had not been cleaned in some time. In fact, during my once weekly cleaning, done on Sunday, I was informed there was no accessible toilet brush. I was given a broom, a foxtail dust broom and pan, some 'cleanser' and paper towels. My toilet in cell 1-47 South would remain a fetid obnoxious bowl that, when a draft hit just right, smelled like a sewer.

Alone and left without my eyeglasses, I was unable to read anything during my first ten days. Quickly, I learned there is a disconnect between the RHU and the property department. It would not be until 21 June 2020 that my glasses were delivered. Unfortunately, they turned out to be the wrong prescription.

Perhaps the most significant change being made in RHU is the opportunity for a loaner radio. I would come to discover, however, that having a radio comes with subtle resentment from some guards who do not agree to changes like this that result in more so-called privileges for prisoners. I soon realized a faint hint of passive aggression by some - not all - officers who made acquiring replacement batteries nearly impossible.

WIFI is now fully integrated in virtually every housing unit throughout the Massachusetts Department of Corrections. In MCI-Concord, WIFI has been installed in the RHU. Prisoners in Massachusetts are allowed to purchase Android tablets. These 'mini-tablets' are ubiquitous. Prisoners download movies, music, games, and send and receive e-mail from approved family and friends. The fact that we are allowed to use our tablets while serving disciplinary detention is a game changer that brings a muchneeded sense of humanity to what has been for too long a painfully cruel and isolating experience.

However, correctional officers who resent change often take out their frustration on prisoners by ignoring requests to hook-up the devices at a charging station provided by the institution. In one instance, a particularly 
disaffected officer routinely refused to charge the prisoners' tablets, conjuring-up restrictions and stating, "Tablets are charged on Wednesdays and Saturdays only".

It is important to point out that the segregation unit was peaceful and quiet during my time there. Although I attribute much of this calm to the prisoners being allowed access to their radios and tablets, there are other changes that came with the introduction of the RHU's. For instance, programs that promote behaviour modification permitted prisoners to access a library of books easily downloaded to tablets. Both indoor and outdoor recreation was added. Good time opportunities were available for program participation such as $7 \frac{1}{2}$ days for taking part in "spectrum".

Some practices that make solitary confinement units intolerable remain. Prison officials, for instance, make rounds silently. There is rarely an announcement that a senior administrator is on the cellblock. These silent rounds, along with the lack of visits from mental health care staff, foreclose any opportunity to address concerns. Heavy steel doors have a one square foot window where prisoners stand to observe who is on the unit. Medication arrives three times daily, and, along with the meals, are served through a slot in the door.

It is difficult to complain about some of the conditions of confinement when so much change is coming so quickly. However, during my brief fifteen-day stay, there were some developments that were at odds with the stated humanizing intent behind these reforms. One notable example I witnessed involved workers delivering three stainless steel recreation tables that were set on the long narrow tier that included holes cut into the steel to facilitate the shackling of prisoners during our 'indoor recreation' time. In the midst of one such hour-long recreation period, I met a man who was fighting a sex offender designation that would see him placed in the "Secure Adjustment Unit" (SAU), which as explained below, is essentially a non-disciplinary segregation area for protective custody prisoners that is experienced as punishment nonetheless.

Recently, MCI-Concord along with the maximum-security SouzaBaranowski Correction Center and other institutions have developed these controversial restrictive housing cellblocks. These "non-disciplinary" restrictive housing units have been carved out of existing units within each institution. Beginning in January 2019, MCI-Concord began to empty the J-4 cellblock in anticipation of creating a secure adjustment unit for imprisoned people with special needs. 
The SAUs are highly structured units that provide access to cognitive behavioural treatment, education, programming, structured recreation, and mental health services. Problematically, however, they are used for prisoners said to be diverted or released from restrictive housing when, in reality, they prolong the cruel practice of restrictive housing, by another name, to isolate and restrain. Those prisoners who suffer mild cognitive disorders are routinely placed in SAU, as are those returning from disciplinary detention confinement. Prisoners dumped and confined in SAU are issued green uniforms that instantly place them in their own segregated category. This otherness is reinforced, not only by different colour uniforms, but also by their use of separate recreation facilities that general population prisoners deride as inferior.

I met a young man whom I interviewed for this essay. He told me he signed up for the SAU simply to get out of the restrictive housing unit. $\mathrm{He}$ is tall, under thirty, and a drug user. He was placed in RHU for having introduced a controlled substance into the institution. He explained that he was placed in a two-person cell where he was surrounded by other drug users who, like himself, were caught up by various disciplinary infractions, sex offenders who may have refused treatment in other facilities, and other men coming or going to DDU. Reflecting on his experience, he came to the conclusion that, "SAU is a way station for misfits... They give you 'points' toward the purchase of candy and food in canteen just to participate, that's how bad it is".

A few days into my stay in the RHU, I received my disciplinary report for the altercation in the woodshop. It stated, in part, that "it was determined through the interview process, video surveillance, and inmate injuries that inmate Diorio was involved in a physical altercation". I did not bother contesting the ticket. Injured, helpless, and unable to read the report as I still had not received my proper eyeglasses, I accepted my time in solitary without complaint.

Frustrated, I would come to discover prisoners in the RHU are routinely denied blankets, pillows, sheets, eyeglasses and other essential property. ${ }^{6}$ Elderly prisoners are particularly vulnerable, as most require reading glasses.

I can attest, however, that the medical care in MCI-Concord and in Souza-Baranowski when I was imprisoned there was, comparatively, first rate. Nurses made rounds three times daily. Accompanied by a supervising correctional officer, nurses dispense medication and hand out sick-call slips, medical grievance forms, and conduct basic treatment. In these respects, 
my care during my fifteen days of confinement in the RHU was nothing but good news. So too was my experience with the mental health staff.

On my arrival in the RHU, I was greeted by a staff member who identified herself as the mental health intake person. Smart and friendly, she asked whether I had plans to hurt myself, whether I had ever been in a segregation unit before, and how my general spirit was given the circumstances. Her demeanour was compassionate and professional. Thanking her, I told her I felt her work was so important in these forbidden places.

Once I received a 'loaner radio' I found a distraction and my time passed without incident. Overall, the best description of solitary confinement irrespective of the label - is that it is a grim waste of time. What was most striking was the melancholy resentment some correctional officers seemed to feel about the changes being made to segregation units. Just as there is a 'convict code', there is a silent code of conduct among rank-and-file correctional officers. Just as there is a tall wall separating these institutions from the public, there is a vast gulf separating guards from prisoner. There is a very real sense that kindness is trained out of the correctional officers who are tasked with running these facilities. A hostile antipathy toward prisoners is palpable.

To illustrate this point, I overheard a conversation between two officers escorting me to recreation. Both were frustrated with the reforms having seemingly materialized and dropped on them without their input. The first officer said to the second that prison administrators are "bozos" for thinking they can allow prisoners in segregation to enjoy indoor recreation on the tier without accounting for the consequences such as fracturing anonymity on the ranges. Referring to the aforementioned three stainless steel tables with shackling holes, one lamented with contempt to the other, "These bozos don't want to hear from the people who have to work here".

In that moment, I could feel tension as I was stuck between these two officers, along with the gulf between their standpoint and mine. "Change is coming", I told myself, "and that's a good thing".

\section{ENDNOTES}

1 The law that authorizes Department of Justice investigations is the Civil Rights of Institutionalized Persons Act, 42 U.S.C. § 1997.

2 A definition for "Restrictive Housing", among other rules may be found in section 87 of An Act Relative to Criminal Justice Reform, Chapter 69 M.G.L $\S 1$, et. seq. (2018). 
3 See Piché, Justin and Karine Major (2015) "Prisoner Writing in/on Solitary Confinement: Contributions from the Journal of Prisoners on Prisons, 1988-2013", Canadian Journal of Human Rights, 4(1): 1-31.

4 See Bonds v. Dubois, United States District Court for the District of Massachusetts. As noted in the January 1955 Report and Recommendations of the Governor's Committee to Study the Massachusetts Correctional System on pages 33-34, "Isolation implies a separate section of a cell block for the detention of those violating institutional rules, and to include deprivation of the usual privileges afforded the general population. Generally, one full meal is provided daily, the prisoners are confined in light, wellventilated cells. Confinement in such units should be for a specified period with a maximum limit of fifteen days".

5 My property inventory form indicated they sent my blanket, but I never received it.

6 Personal property is treated like garbage by prison officials. It is a tactic and practice by prison administrators, and staff, to 'lose' prisoners' personal property. There is little recourse. Many prisoners attempt to grieve the loss, however, jailors simply dismiss the property claims stating that "no evidence" exists to substantiate the accusation, or some other pro forma denial.

\section{REFERENCE}

Piché, Justin and Karine Major (2015) "Prisoner Writing in/on Solitary Confinement: Contributions from the Journal of Prisoners on Prisons, 1988-2013", Canadian Journal of Human Rights, 4(1): 1-31.

\section{ABOUT THE AUTHOR}

Charles N. Diorio is currently a prisoner living in the Souza-Baranowski Correctional Centre. He can be reached at the addresses listed below:

Charles N. Diorio W103769

Souza-Baranowski C.C.

P.O. Box 8000

Shirley, Massachusetts 01464

USA

Attorney James J. Gavigan, Esq.

80 Billings Road

N. Quincy, Massachusetts

USA 